\title{
Effect of Functionalized Graphene on the Mechanical Properties of Okra Cellulose Nanofibers/Epoxy Nanocomposites
}

\author{
Ajmeera Ramesh, N.V. Srinivasulu, M. Indira Rani
}

\begin{abstract}
Towards the use of renewable, biodegradability, low cost, and ecofriendly materials, the recent trend has inclined to the cellulose nanofibers based material in different applications.. The purpose of the present research is to develop a new nanocomposite material. In the present study, the authors have investigated the effect of dispersion of Functionalized Graphene (GP) of epoxy nanocomposites laminates fabricated from Okra Cellulose Nanofibers (CNFs). Nanocomposite materials have been identified as alternative materials for automotive, aerospace, structural, and biomedical applications. The weight of functionalized GP in CNFs was varied from $0.25 \mathrm{wt} \%$ to $1 \mathrm{wt} \%$. Mechanical properties measured are for tensile, flexural, impact, and microhardness was used for characterization of functional group and structural analysis in functionalized GP. The distribution and confirmation of functionalized GP in CNFs were analyzed using a Scanning Electron Microscope (SEM). The nanocomposites were characterized using tensile, flexural, impact, and microhardness tests based on ASTM standards. Mechanical characterization using nanoindentation techniques also showed significant improvement in mechanical properties of nanocomposites in comparison to CNFs. The $0.75 \mathrm{wt} \%$ nanocomposites showed an increase in elastic modulus and hardness, respectively, in comparison to CNFs. The surface morphology of fractured specimens were examined using SEM which revealed good interaction between the GP/CNFs and the epoxy matrix. Overall, this study suggests a prosperous and green route for the fabrication of functionalized GP in CNFs reinforced composites with improved properties such as stiffness, strength, and hardness.
\end{abstract}

Keywords: Okra plants, Cellulose Nanofibers (CNFs), Graphene (GP), Epoxy Nanocomposites, mechanical properties.

\section{INTRODUCTION}

$\mathrm{B}$ engineering applications such as aerospace, automotive, structural, gears, packing, and construction[1-3]. The increasing demand for high performance in nonmaterial

Revised Manuscript Received on April 27, 2020.

* Correspondence Author

Ajmeera Ramesh*, Department of Mechanical Engineering, CMR Technical Campus and a Research scholar in JNTU Hyderabad, India. E-mail: ramesh340mech@gmail.com.

Dr. N.V. Srinivasulu, Department of Mechanical Engineering, Chaitanya Bharathi Institute of Technology, Hyderabad, India. E-mail: vaastusrinivas@gmail.com

Dr. M. Indira Rani, Department of Mechanical Engineering, JNTUH College of Engineering, Hyderabad, India. E-mail: marpuindira@gmail.com.

(C) The Authors. Published by Blue Eyes Intelligence Engineering and Sciences Publication (BEIESP). This is an open access article under the CC BY-NC-ND license (http://creativecommons.org/licenses/by-nc-nd/4.0/) from renewable origins and their mechanical properties have led to intensive research in the area of nanofillers available worldwide[4, 5]. They have involved much interest from scientists, academics and industry globally[6]. Polymer nanocomposites are focused on the manufacturing of advanced composite materials [7]. Hence, the performance of polymer nanocomposites was showing to be a needed factor for developing and preparing advanced polymer composites[8]. The functionalized Graphene is used as a nanofiller material, and epoxy polymer composite is prepared using the solution intercalation method, and the effect of nanofiller on the mechanical properties of epoxy nanocomposites was studied[9]. In addition, these CNF is also named as the further-scope renewable reinforcement filler as it shows potential substitute to costly nonmaterials like Graphene and carbon nanotubes, for the manufacture of best evaluated mechanical properties of polymer-based on nanocomposites [10-11]. Among different kinds of particulate materials, Graphene has in recent times, working as reinforcement in epoxy polymer to improve the fracture-related properties of the developed epoxy-graphene nanocomposites[11, 12]. In recent years, epoxy nanocomposites have gained attractive attention because they give enhancement in mechanical properties compared to conventional composites [13-15]. Studies concerning the manufacturing of polymeric nanocomposites with resin casting methods are limited as nanoparticles increase the viscosity of polymer solution, thus hinders the easy flow of polymer into the fibrous material[16]. The different kind of polymer matrices that are presently available, epoxy resins stay leading for the improvement of high-performance materials because of their, mechanical, thermal stability properties and electrical [17]. Several results show the environmental friendliness, sustainability, and the cost aspect of acoustic panels[18, 19]. Resin casting is the filling of a mould with liquid resin that is hardened, and then the part can be removed. They have studied the mechanical propetites of graphene nanoplatelets (GnPs) [20, 21]. Recently, the addition of graphene oxide filler on the fiber surface has been reported to improve the mechanical properties of nanocomposites[22, 23]. The effect of nanoparticle addition in goat hair is studied by the addition of graphene nanopowder with goat hair in small proportions, and their mechanical behaviour is studied [24, 25]. Various GO contents of 0.05 , 0.1 and 0.2 wt. $\%$ are added. The obtained values shows, in addition of GO to pure epoxy increased the viscosity and affected the resin cure reaction by reducing curing gel time.

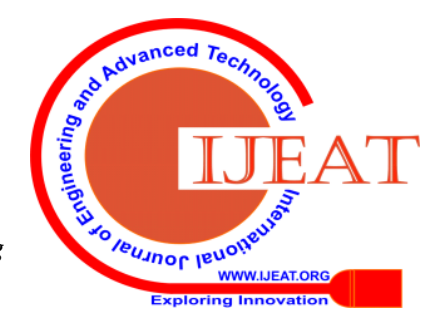


There is an increase of mechanical properties values by adding 0.2 wt. \% GO to glass fiber/epoxy composite P/CNFs nanocomposites have been extensively studied for their mechanical and thermal properties of CNW films. In this research work, the effects of the different weight percentage of functionalized GP in CNFs was varied from 0.25 to 1 wt. \% of the epoxy resin. Mechanical Stirring and Ultra-sonication Techniques were used to disperse graphene in the matrix. Currently the study is on the influence of graphene particulate, and CNFs reinforced epoxy with different filler composites on the mechanical properties such as tensile, flexural, compression, impact, and water absorption. SEM analysis was go through to examine uniform distribution of GP and CNFs particulates in the epoxy matrix and to visualize the fracture morphology of failed samples.

\section{MATERIALS AND EXPERIMENTAL WORK}

\section{A. Material}

The nanocomposites material was prepared by using Araldite Epoxy Resin (LY 556) and Hardener (HY 951) which is procured from the local market in Hyderabad, India. Epoxy and hardener are mixed in the ratio of 10:1propotions. The graphene is obtained from Sigma-Aldrich Chemicals which were produced by the catalytic CVD method and functionalized with the $\mathrm{COOH}$ group, the average diameter and length of graphene range between 15 to $25 \mathrm{~nm}$ and 10 to 20 um respectively. Graphene is a one atomic graphite layer. It is one of the forms of carbon crystalline allotrope in which the carbon atoms sp2 hybridized has a structure hexagonal honeycomb lattice. It has a different kind of properties like less density, good in conductivity and electricity in combination with high strength.

\section{FABRICATION OF EPOXY/OKRA CNFS NANOCOMPOSITES}

The Functionalization GP/CNFs suspensions had solvents exchanged from water to Acetone. LY556 epoxy resin was added to different amounts of the graphene suspensions for the preparation of $0.25,0.50,0.75$, and 1 wt. $\%$ of GP/CNFs epoxy nanocomposites using the resin casting method. Each GP/CNFs nanocomposites obtained was mixed with an HY 951 hardener. The resultant mixture was stirred by using a magnetic stirrer at $900 \mathrm{rpm}$ for 1 hour at room temperature and sonicated to remove air trapped bubbles in the ultrasonic ice bath. The moulds released wax polish applied to surface of the metal molds wall to smooth separation of the nanocomposites samples. Following the removal of trapped bubbles, the resultant mixture was poured into Aluminium metal moulds of the desired shape and kept in the oven at room temperature for 24 hours at $80^{\circ} \mathrm{C}$ for 4 hours. LY556 epoxy resin and HY 951 hardener used for the neat epoxy resin composite samples were in the mixing ratio of 10:1 by weight. A mechanical, magnetic stirrer was followed by the same method mentioned for GP/CNFs nanofillers.

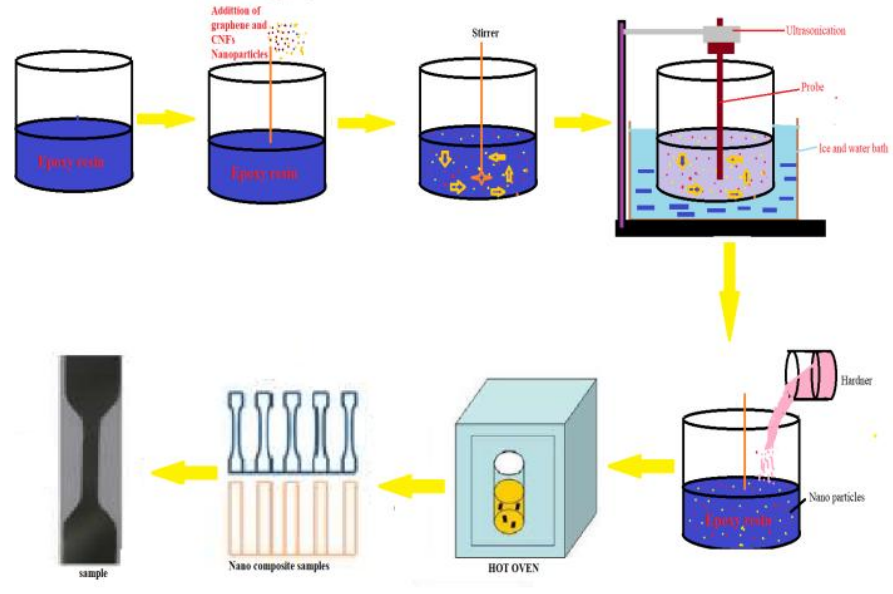

Fig. 1 Fabrication of Nanocomposites

\section{CHARACTERIZATION AND TESTING}

\section{A. Scanning Electron Microscopy (SEM)}

The morphology of the fracture surfaces of the manufactured composites is obtained using FEI Quanta 250 FEG.

\section{B. Tensile Test}

The tensile properties of the fabricated composite laminate were measured according to ASTM 638 Instron 4505 tensile tester. The tests were performed at a cross-head speed of 5 $\mathrm{mm} / \mathrm{min}$ and a load cell of $10 \mathrm{KN}$. Three specimens had been tested for each type of fabricated sample, and the average value was calculated from the tensile test.

\section{Flexural Test}

flexural tests were conducted according to ASTM D790 standards using a universal testing machine INSTRON 4505. The experiments were performed at a cross-head speed of 5 $\mathrm{mm} / \mathrm{min}$ and a load cell of $10 \mathrm{KN}$. Three specimens from each sample were tested.

\section{Compression Test}

The compression tests were conducted according to ASTM D695 standards using a universal testing machine, INSTRON 4505. The experiments were performed at a cross-head speed of $5 \mathrm{~mm} / \mathrm{min}$ and a load cell of $10 \mathrm{KN}$. Three specimens from each sample were tested. The standard specimen is $12.7 \mathrm{~mm}$ in diameter and $25.4 \mathrm{~mm}$ long.

\section{E. Microhardness Test}

Microhardness properties of nanocomposites were characterized by subjecting CNFs, and graphene in CNFs reinforced nanocomposites under different loads. Each sample was labeled by name, number, and indentation locations. The indentation locations are with a reference along a line drawn from left to the right end of the tested specimen. The first indentation location was taken along the longitudinal axis at $4 \mathrm{~mm}$ toward the center of the sample. Remaining points were followed by $4 \mathrm{~mm}$ intervals from the first point toward the right end.

\section{F. Impact Test}

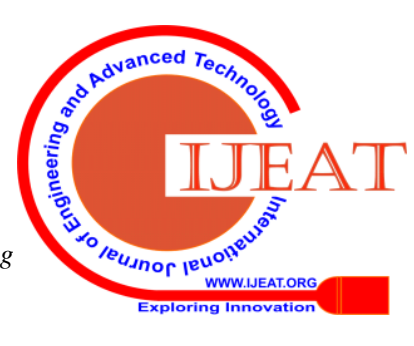


The impact tests were performed as per ASTM D256 standards with incident energy of 5.4J using impact testing machine, and an impact speed of $4 \mathrm{~m} / \mathrm{s}$ with the specimen size of $63.5 \times 12.7 \times 3 \mathrm{~mm}$ is cut from the fabricated nanocomposite laminate. Three specimens had been tested for each type of fabricated sample, and the average value was calculated from the Izod test.

\section{RESULTS AND DISCUSSION}

Table.1.Mechanical properties of nanocomposites

\begin{tabular}{|c|c|c|c|c|c|c|c|c|}
\hline $\begin{array}{l}\text { S. } \\
\text { No }\end{array}$ & $\begin{array}{l}\text { Composite } \\
\text { samples }\end{array}$ & $\begin{array}{c}\text { Tensile } \\
\text { Strength } \\
\text { (MPa) }\end{array}$ & $\begin{array}{c}\text { Tensile } \\
\text { Modulus } \\
\text { (GPa) }\end{array}$ & $\begin{array}{c}\text { Flexural } \\
\text { Strength } \\
\text { (MPa) }\end{array}$ & $\begin{array}{c}\text { Flexural } \\
\text { Modulus } \\
\text { (GPa) }\end{array}$ & $\begin{array}{c}\text { Compression } \\
\text { Strength (MPa) }\end{array}$ & $\begin{array}{c}\text { Impact } \\
\text { Strength }(J)\end{array}$ & $\begin{array}{c}\text { Vickers micro } \\
\text { Hardness } \\
\text { (HV) }\end{array}$ \\
\hline 1 & CNFs-E & $32.83 \pm 0.90$ & $3.43 \pm 0.40$ & $52.20 \pm 1.01$ & $3.10 \pm 0.17$ & $79.40 \pm 0.10$ & $3.0 \pm 0.10$ & $17.40 \pm 0.66$ \\
\hline 2 & $\begin{array}{c}\text { CNFs-E }+0.25 \% G \\
\text { P }\end{array}$ & $32.84 \pm 0.90$ & $3.44 \pm 0.51$ & $54.70 \pm 0.90$ & $3.11 \pm 0.35$ & $79.53 \pm 2.10$ & $3.10 \pm 0.20$ & $17.46 \pm 0.29$ \\
\hline 3 & $\begin{array}{c}\text { CNFs-E }+0.50 \% G \\
\mathrm{P} \\
\end{array}$ & $35 \pm 0.10$ & $3.45 \pm 0.28$ & $58.40 \pm 0.71$ & $3.13 \pm 0.20$ & $80.12 \pm 2.46$ & $3.20 \pm 0.30$ & $18.90 \pm 1.01$ \\
\hline 4 & $\begin{array}{c}\text { CNFs-E }+0.75 \% G \\
\mathrm{P}\end{array}$ & $39.90 \pm 0.44$ & $3.46 \pm 0.27$ & $60.37 \pm 0.10$ & $3.19 \pm 0.10$ & $82.0 \pm 0.70$ & $3.40 \pm 0.02$ & $19.67 \pm 0.64$ \\
\hline 5 & CNFs-E+1\%GP & $34.75 \pm 0.70$ & $3.40 \pm 0.46$ & $52.77 \pm 0.78$ & $3.13 \pm 0.35$ & $70.40 \pm 0.10$ & $3.30 \pm 0.01$ & $18.30 \pm 0.53$ \\
\hline
\end{tabular}

\section{A. Tensile Test}

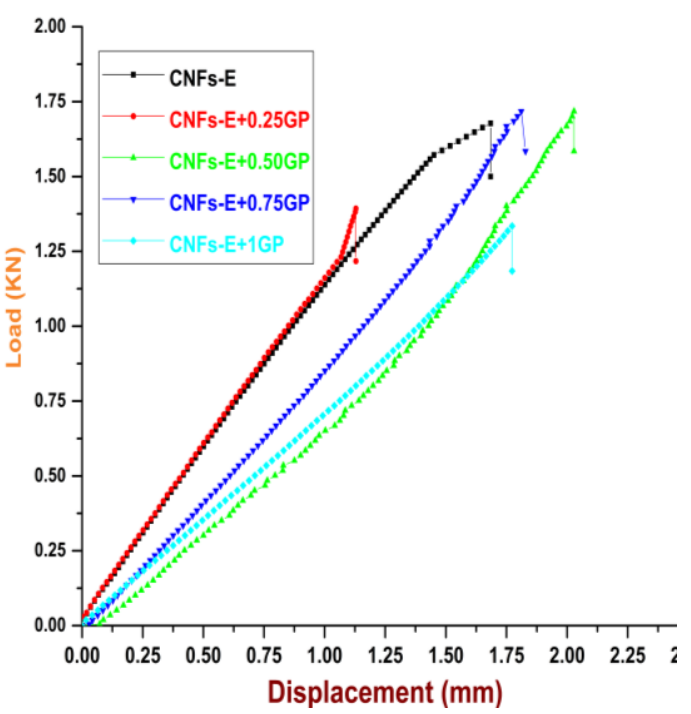

Fig. 2. Typical load and displacement curve of Epoxy/CNFs and Epoxy/CNFs/GP Nanocomposites.

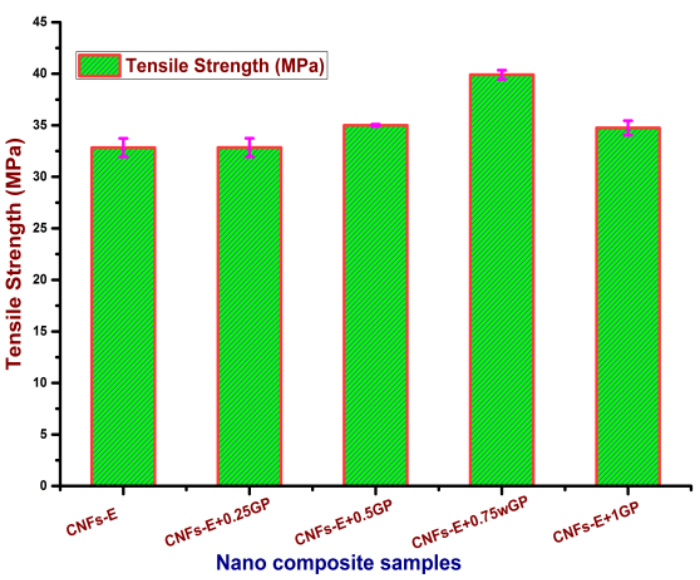

Fig. 3 Tensile Strength of the CNFs and Epoxy/GP Composites

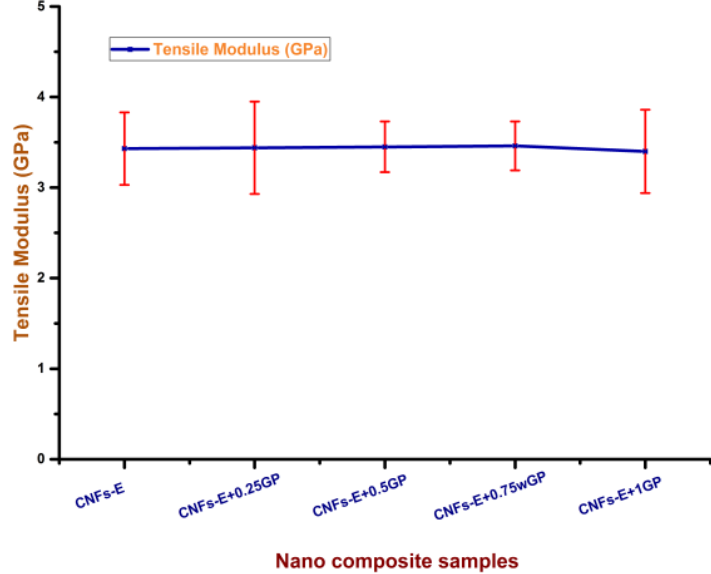

Fig.4 Tensile Modulus of the CNFs and Epoxy/GP Composites containing $0.25,0.5,0.75$ and 1 wt $\%$ GP

Fig. 2 \& 3 shows the typical tensile load \& displacement and tensile stress \& tensile strain curves of both CNFs and the addition of $(0.25,0.5,0.75$, and 1 wt \%) GP in CNFs epoxy nanocomposites. Fig. 4 shows the typical tensile modulus of epoxy/CNFs and epoxy / CNFs / GP nanocomposites. In the present analysis, the nanocomposite specimen with designation CNFs - E +0.75 GP has the highest tensile strength of $39.90 \pm 0.44 \mathrm{MPa}$ and tensile modulus of $3.46 \pm$ 0.27GPa followed by CNFs - E, CNFs - E + 0.25 GP, CNFs $\mathrm{E}+0.5 \mathrm{GP}$ and CNFs - E + $1 \mathrm{GP}$ nanocomposite specimens with a tensile strength of $32.83 \pm 0.90 \mathrm{MPa}, 32.84 \pm 0.90$ $\mathrm{MPa}, 35 \pm 0.10 \mathrm{MPa}$, and $34.75 \pm 0.70 \mathrm{MPa}$ and with a tensile modulus of $3.43 \pm 0.40 \mathrm{GPa}, 3.44 \pm 0.51 \mathrm{GPa}, 3.45 \pm 0.27$ GPa, and $3.40 \pm 0.46 \mathrm{GPa}$ respectively. The addition of GP in CNFs up to $0.75 \mathrm{wt}$ \% caused an increase in the tensile strength and tensile modulus of the CNFs by $39.90 \pm 0.44$ $\mathrm{MPa}$ and $32.48 \pm 0.42 \%$ and $3.47 \pm 0.40 \mathrm{GPa}$ and $7.87 \pm 0 \%$ respectively. The addition of functionalized GP in CNFs to the epoxy polymer matrix has improved flexural strength and flexural modulus. It is observed that tensile strength and tensile modulus of epoxy polymer nanocomposites with lesser functionalized GP loading in CNFs are higher than the epoxy polymer nanocomposites with random dispersion, which clearly indicates the effect of functionalized GP alignment. 
Reduced dispersion of GP at other loadings in CNFs / epoxy nanocomposites caused agglomeration in GP / CNFs. GP agglomerate in the epoxy resin nanocomposite lead to a reduction in load transfer between GP / CNFs and epoxy polymer nanocomposites tensile strength and stiffness enhancements were the results of a functional interaction between GP / CNFs epoxy nanocomposites[26]. On the other hand, there was a decrease in deformation at the break following an increase in the functionalized GP concentrations content $1 \mathrm{wt}$ \% $\%$ in CNFs / epoxy nanocomposite.

\section{B. Flexural Test}

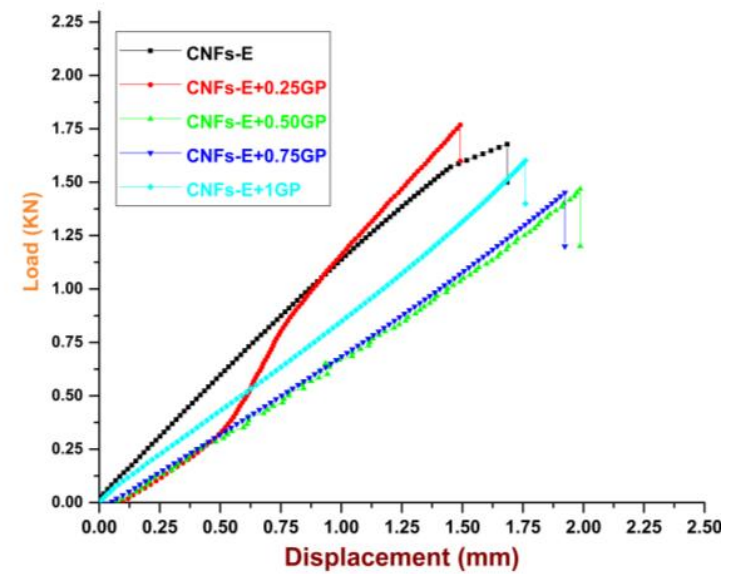

Fig. 5 Typical load and displacement curve of Epoxy/CNFs and Epoxy/CNFs/GP Nanocomposites

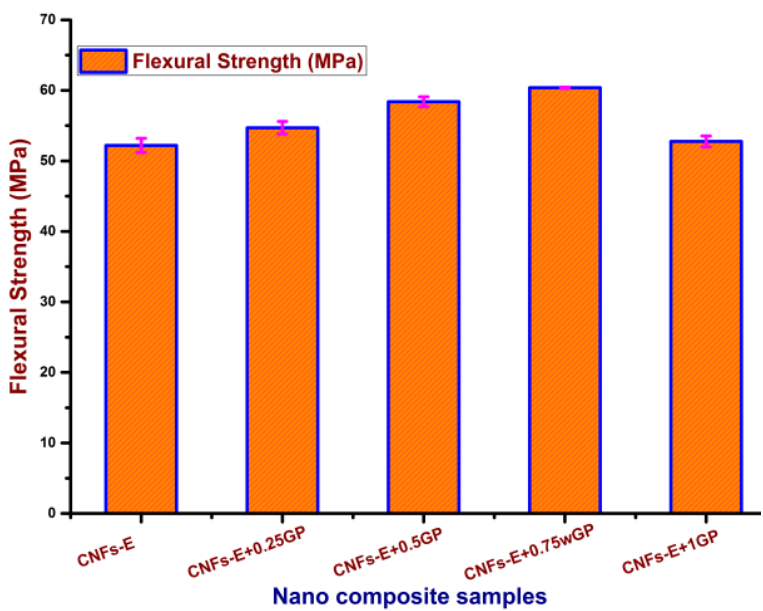

Fig.6 Flexural Strength Of The CNFs And Epoxy/GP Composites

Fig. 5 \& 6 shows the typical flexural load \& displacement and flexural stress \& flexural strain curves of both CNFs and the addition of $(0.25,0.5,0.75$, and $1 \mathrm{wt} \%)$ GP in CNFs epoxy nanocomposites.

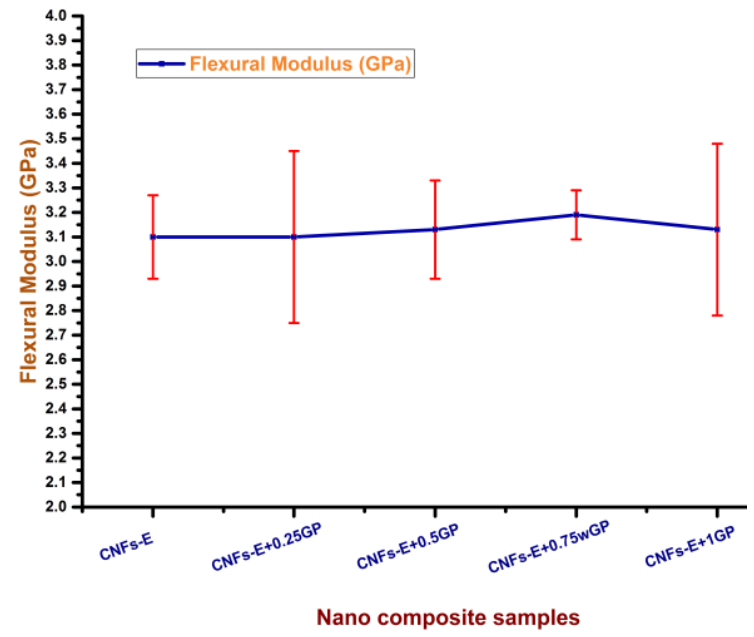

Fig.7 Flexural Modulus of the CNFs And Epoxy / GP Composites

Fig. 7 shows the typical flexural modulus of epoxy / CNFs and epoxy / CNFs / Graphene nanocomposites. In the present analysis, the nanocomposite specimen with designation CNFs $-\mathrm{E}+0.75 \mathrm{GP}$ has the highest flexural strength of $60.37 \pm 0.10$ $\mathrm{MPa}$ and flexural modulus $3.19 \pm 0.10 \mathrm{GPa}$ followed by CNFs - E, CNFs - E + 0.25 GP, CNFs - E + 0.5 GP and CNFs - E + 1GP nanocomposite specimens with a flexural strength of $52.20 \pm 1.01 \mathrm{MPa}, 54.70 \pm 0.90 \mathrm{MPa}, 58.40 \pm 0.71 \mathrm{MPa}$, and $52.77 \pm 0.78 \mathrm{MPa}$ and with a flexural modulus of $3.10 \pm$ $0.17 \mathrm{GPa}, 3.11 \pm 0.35 \mathrm{GPa}, 3.13 \pm 0.20 \mathrm{GPa}$, and $3.13 \pm 0.35$ GPa respectively. The addition of GP in CNFs up to 0.75 wt. $\%$ caused an increase in the flexural strength and flexural modulus of the CNFs by $60.37 \pm 1.45 \mathrm{MPa}$ and $15.65 \pm 0.30$ $\%$ and $3.23 \pm 0.31 \mathrm{GPa}$ and $4.19 \pm 0 \%$ respectively. The addition of functionalized GP in CNFs to the epoxy polymer matrix has improved flexural strength and flexural modulus. It is observed that flexural strength and flexural modulus of epoxy polymer nanocomposites with lesser functionalized GP loading in CNFs is higher than the epoxy polymer nanocomposites with random dispersion, which clearly indicates the effect of functionalized GP alignment. Poor dispersion of GP at other loadings in CNFs / epoxy nanocomposites caused agglomeration in GP / CNFs in GP agglomerate in the epoxy resin nanocomposite leading to a reduction in load transfer between GP / CNFs and epoxy polymer nanocomposites flexural strength and stiffness enhancements were the results of a functional interaction between GP / CNFs epoxy nanocomposites [26].

On the other hand, there was a decrease in deformation at the break following an increase in the functionalized GP concentrations content 1wt. \% in CNFs / epoxy nanocomposite[27].

\section{Compression Test}




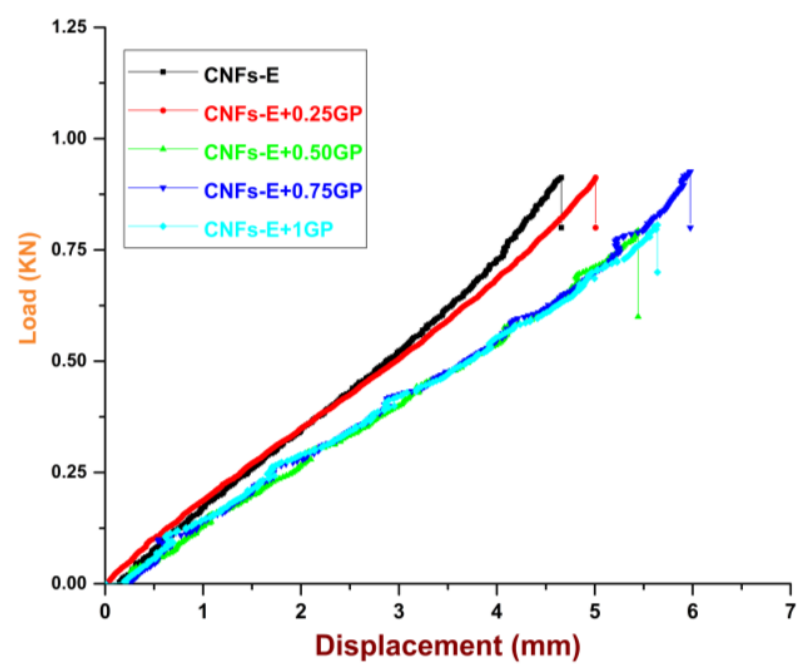

Fig. 8 Typical Plot of the Load And Displacement Of Nanocomposites For Different Functionalized GP Loading in CNFs

Fig. 8 shows the typical compression load and displacement curve of both CNFs and the addition of $(0.25,0.5,0.75$, and 1 wt \%) GP in CNFs epoxy nanocomposites. Fig. 9 shows the typical compression strength of epoxy / CNFs and epoxy / CNFs / graphene nanocomposites. In the present analysis, the nanocomposite specimen with designation CNFs $-\mathrm{E}+$ $0.75 \mathrm{GP}$ has the highest compression strength of $82 \pm 0.70$ $\mathrm{MPa}$ and followed by CNFs - E, CNFs - E + 0.25 GP, CNFs $-\mathrm{E}+0.5 \mathrm{GP}$ and $\mathrm{CNFs}-\mathrm{E}+1 \mathrm{GP}$ nanocomposite specimens with a compression strength of $79.40 \pm 0.10 \mathrm{MPa}, 79.53 \pm 2.10$ $\mathrm{MPa}, 80.12 \pm 2.46 \mathrm{MPa}$, and $70.40 \pm 0.10 \mathrm{MPa}$ respectively.

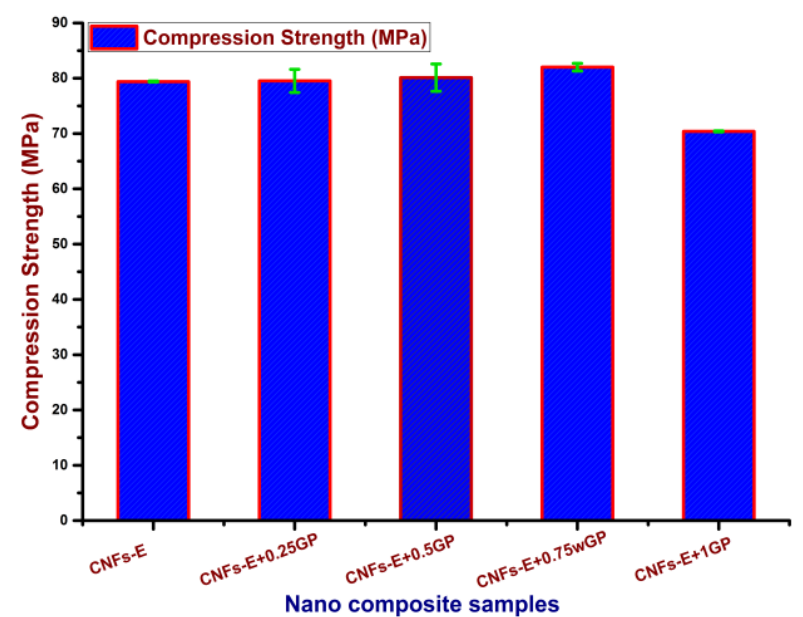

Fig. 9 Compression Strength of the CNFs and Epoxy/GP Composites

The addition of GP in CNFs up to 0.75 wt. \% caused an increase in the compression strength of the CNFs by $82 \pm 3.48$ $\mathrm{MPa}$ and $3.27 \pm 0.97 \%$, respectively. The addition of functionalized GP in CNFs to the epoxy polymer matrix has improved compression strength. It is observed that the compression strength of epoxy polymer nanocomposites with lesser functionalized GP loading in CNFs is higher than the epoxy polymer nanocomposites with random dispersion, which clearly indicates the effect of functionalized GP alignment. Poor dispersion of GP at other loadings in CNFs / epoxy nanocomposites caused agglomeration in GP / CNFs in GP agglomerate in the epoxy resin nanocomposite leading to a reduction in load transfer between GP / CNFs and epoxy polymer nanocomposites compression strength enhancements were the result of a functional interaction between GP / CNFs epoxy nanocomposites[28]. On the other hand, there was a decrease in deformation at the break following an increase in the functionalized GP concentrations content $1 \mathrm{wt}$. \% in CNFs / epoxy nanocomposite[27].

\section{Microhardness Test}

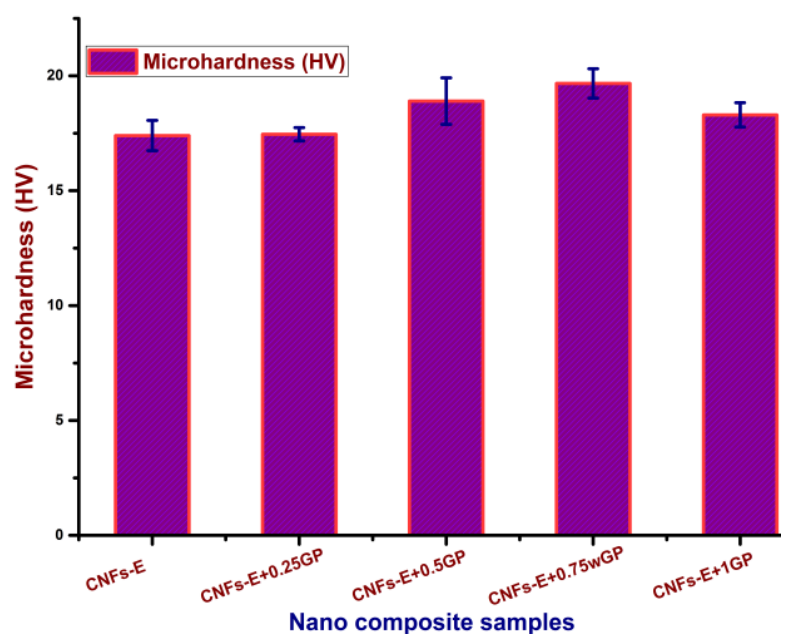

Fig.10 Microhardness of the CNFs and Epoxy/GP Composites

Fig. 10 shows the typical microhardness of both CNFs and the addition of $(0.25,0.5,0.75$, and 1 wt \% ) GP in CNFs epoxy nanocomposites. In the present analysis, the nanocomposite specimen with designation CNFs - E + 0.75GP has the highest microhardness of $19.67 \pm 0.64 \mathrm{HV}$ followed by CNFs - E, CNFs - E + 0.25 GP, CNFs - E + 0.5 GP and CNFs - E + $1 \mathrm{GP}$ nanocomposite specimens with a microhardness of 17.40 $\pm 0.66,17.46 \pm 0.29 \mathrm{HV}, 18.90 \pm 1.01 \mathrm{HV}$, and $18.30 \pm 0.53$ $\mathrm{HV}$ respectively. The addition of GP in CNFs up to 0.75 wt. $\%$ caused an increase in the microhardness of the CNFs by $19.67 \pm 0.64 \mathrm{HV}$ and $13.05 \pm 0.98 \%$, respectively. The addition of functionalized GP in CNFs to the epoxy polymer matrix has improved flexural strength and flexural modulus. It is observed that tensile strength and tensile modulus of epoxy polymer nanocomposites with lesser functionalized GP loading in CNFs are higher than the epoxy polymer nanocomposites with random dispersion, which clearly indicates the effect of functionalized GP alignment. Reduced dispersion of GP at other loadings in CNFs / epoxy nanocomposites caused agglomeration in GP / CNFs in GP agglomerate in the epoxy resin nanocomposite leading to a reduction in load transfer between GP / CNFs and epoxy polymer nanocomposites tensile strength and stiffness enhancements were the results of a functional interaction between GP / CNFs epoxy nanocomposites[29]. On the other hand, there was a decrease in deformation at the break following an increase in the functionalized GP concentrations content 1wt. \% in CNFs / Epoxy nanocomposite.

E. Impact Test

Fig.11 shows the average impact energy of both

Published By:

Blue Eyes Intelligence Engineering \& Sciences Publication

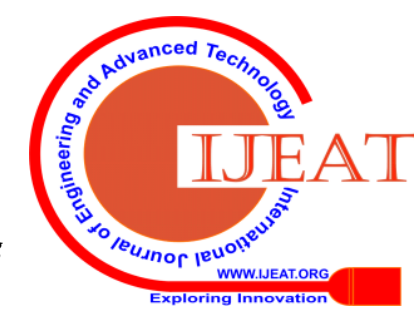




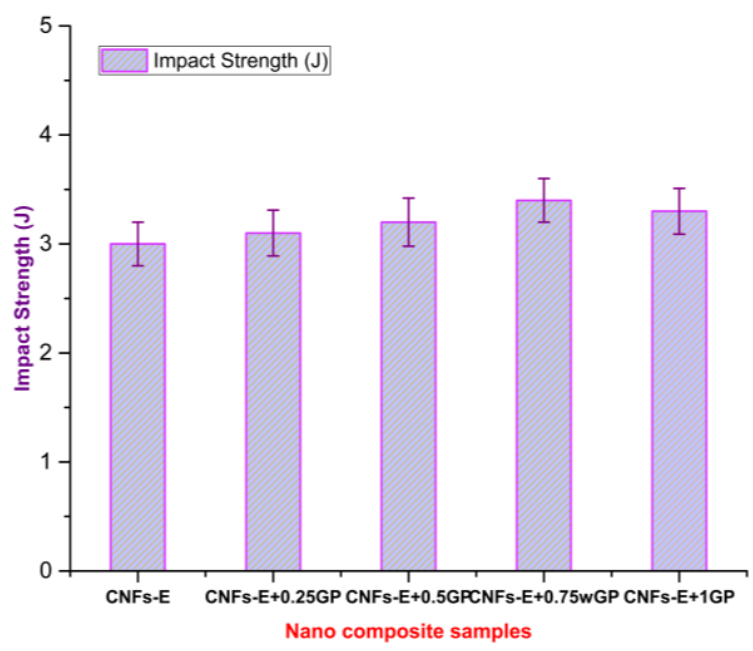

Fig. 11 Impact Energy Of The CNFs And Epoxy / GP Composites

CNFs and the addition of $(0.25,0.5,0.75$, and $1 \mathrm{wt} \%)$ GP in CNFs epoxy nanocomposites. In the present analysis, the nanocomposite specimen with designation CNFs - E + 0.75 GP has the highest impact energy of $3.40 \pm 0.02 \mathrm{~J}$ followed by CNFs - E, CNFs - E + 0.25 GP, CNFs - E + 0.5 GP and CNFs $-\mathrm{E}+1 \mathrm{GP}$ nanocomposite specimens with an impact energy of $3.0 \pm 0.10 \mathrm{~J}, 3.10 \pm 0.20 \mathrm{~J}, 3.20 \pm 0.30 \mathrm{~J}$, and $3.30 \pm 0.01 \mathrm{~J}$ respectively. The addition of GP in CNFs up to 0.75 wt. \% caused an increase in the impact energy of the CNFs by $3.40 \pm$ $0.02 \mathrm{~J}$ and $13.33 \pm 0.8 \%$, respectively.

The addition of functionalized GP in CNFs to the epoxy polymer matrix has improved flexural strength and flexural modulus. It is observed that the impact energy of epoxy polymer nanocomposites with lesser functionalized GP loading in CNFs is higher than the epoxy polymer nanocomposites with random dispersion, which clearly indicates the effect of functionalized GP alignment. Poor distribution of GP at other loadings in CNFs / epoxy nanocomposites caused agglomeration in GP / CNFs in GP agglomerate in the epoxy resin nanocomposite leading to a reduction in load transfer between GP / CNFs and epoxy polymer nanocomposites tensile strength and stiffness enhancements were the results of a functional interaction between GP / CNFs epoxy nanocomposites [30]. On the other hand, there was a decrease in deformation at the break following an increase in the functionalized GP concentrations content $1 \mathrm{wt}$. \% in CNFs / epoxy nanocomposite.

\section{F. Scanning Electron Microscopy (SEM)}

Analysis of failure behaviour through scanning electron microscopy of functionalized graphene (GP) / CNFs epoxy nanocomposite was investigated by SEM. The fracture surface of CNFs epoxy nanocomposite shows the smooth surface with long crack propagation, as shown in Fig. 12

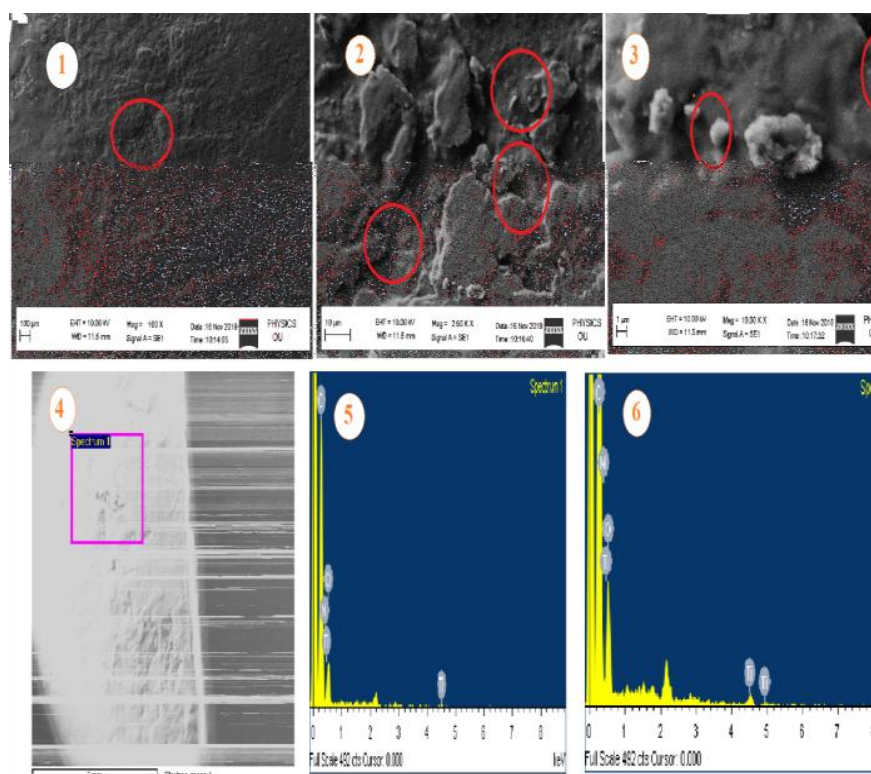

Fig. 12 Surface Morphology Of The Cnfs And Epoxy/GP Composites

The formation of agglomeration of GP / CNFs oppose the flow of matrix into the agglomerated GP and avoid the forming of holes in between GP / CNFs and epoxy polymer matrix. The comfortable closeness and poor adhesion between the GP and CNFs fillers and matrix shows result as better mechanical properties. For the micrographs of GP and CNFs, nanofillers reinforced epoxy nanocomposite agglomeration of GP and CNFs could be observed when added 0.75 wt \% GP / CNFs / Epoxy polymer nanocomposite. These investigate state that an interaction between the CNFs / Epoxy resin matrix and the reinforcement an increasing in GP filler coating by 0.75 wt \% GP in CNFs / Epoxy polymer nanocomposite and decreased mechanical properties with an increase in GP content.

\section{CONCLUSION}

In this research work, CNFs were prepared using the acid hydrolysis process from okra plant. The laminates that were made using nanofillers are Graphene (GP), Cellulose Nanofibers (CNFs) and Green Epoxy Resin. A surface of the morphology of nanocomposite was made using SEM. The tensile strength, tensile modulus, flexural strength, flexural modulus, compression strength, microhardness, and impact strength increased with increasing GP in CNFs loading up $0.75 \mathrm{wt} \%$ as an increased in the deformation at the break with a higher GP adding in CNFs addition, there was decreased in the tensile strength, tensile modulus, flexural strength, flexural modulus, compression strength, microhardness and impact strength decrease. As a substitute for epoxy and loading GP in CNFs nanocomposites, the loading up 0.75 wt. $\%$ of GP in CNFs nanocomposite laminate was a stronger substitute where the tensile, flexural, impact and microhardness properties were projected. The morphological (SEM) studies confirmed the strength of nanocomposites and there was an increase in nanocomposites with the addition of 0.75 wt. \% of graphene in CNFs fillers.

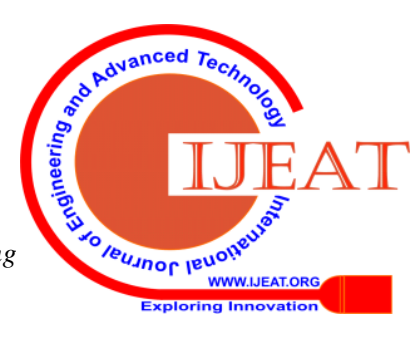


The failure modes of adding GP in CNFs nanocomposites samples were investigated to enable a study of the crack propagations CNFs nanocomposite of each sample. Epoxy nanocomposite sample containing 0.75 wt. \% of CNFs showed rougher surfaces.

\section{REFERENCES}

1. S. Veličković Gajević, B. Stojanovic, L. Ivanovic, S. Miladinović, S. Milojević, application of nanocomposites in the automotive industry, 2018.

2. V. Rathod, J. Kumar, A. Jain, Polymer, and ceramic nanocomposites for aerospace applications, Applied Nanoscience 7 (2017) 519-548.

3. C. Delides, Everyday Life Applications of Polymer Nanocomposites, 2016.

4. E. Jamróz, P. Kulawik, P. Kopel, The Effect of Nanofillers on the Functional Properties of Biopolymer-based Films: A Review, Polymers 11 (2019) 675.

5. S.Z. Al Sheheri, Z.M. Al-Amshany, Q.A. Al Sulami, N.Y. Tashkandi, M.A. Hussein, R.M. El-Shishtawy, The preparation of carbon nanofillers and their role on the performance of variable polymer nanocomposites, Des Monomers Polym 22(1) (2019) 8-53.

6. J. Wei, T. Vo, F. Inam, Epoxy/graphene nanocomposites - processing and properties: a review, RSC Adv. 5 (2015) 73510-73524.

7. D.G. Raghavendra, mechanical, and tribological behavior of nanofiller reinforced polymer nanocomposite, 2015.

8. J. Njuguna, K. Pielichowski, The Role of Advanced Polymer Materials in Aerospace, 2013.

9. R.G. Manjunatha G.1, Iranna Hiremath2, Functionalized Graphene for Epoxy Composites with Improved Mechanical Properties, American Journal of Materials Science(2016).

10. P.K. Bajpai, F. Ahmad, V. Chaudhary, Processing and characterization of bio-composites, 2019, pp. 123-139.

11. R. Atif, I. Shyha, F. Inam, Mechanical, Thermal, and Electrical Properties of Graphene-Epoxy Nanocomposites-A Review, Polymers 8 (2016) 281.

12. J. Wei, T. Vo, F. Inam, Epoxy/graphene nanocomposites - processing and properties: a review, RSC Advances 5(90) (2015) 73510-73524.

13. M.A.H.M. El-meniawi, K. R. Megahed, M., Positron annihilation spectroscopy and mechanical properties studies for epoxy matrices reinforced with different nanoparticles, Journal of Polymer Research 23(9) (2016)

14. S. Fu, Z. Sun, P. Huang, Y. Li, N. Hu, Some basic aspects of polymer nanocomposites: A critical review, Nano Materials Science 1(1) (2019) 2-30.

15. H. Zhang, Z. Zhang, K. Friedrich, C. Eger, Property improvements of in situ epoxy nanocomposites with reduced interparticle distance at high nanosilica content, Acta Materialia 54 (2006) 1833-1842.

16. F. Hussain, M. Hojjati, M. Okamoto, R. Gorga, Polymer Matrix Nanocomposites, Processing, Manufacturing and Application: AN OVERVIEW, J. Compos. Mater. 40 (2006).

17. D.K. Rajak, D.D. Pagar, R. Kumar, C.I. Pruncu, Recent progress of reinforcement materials: a comprehensive overview of composite materials, Journal of Materials Research and Technology 8(6) (2019) 6354-6374.

18. V. Desarnaulds, E. Costanzo, A. Carvalho, B. Arlaud, Sustainability of acoustic materials and acoustic characterization of sustainable materials, 12th International Congress on Sound and Vibration 2005, ICSV 20051 (2005).

19. F. Asdrubali, S. Schiavoni, K. Horoshenkov, A Review of Sustainable Materials for Acoustic Applications, Building Acoustics 19 (2012) 283-312.

20. T.-H. Hsieh, W.J. Chen, C.L. Chiang, M.-Y. Shen, Environmental aging effect on interlaminar properties of graphene nanoplatelets reinforced epoxy/carbon fiber composite laminates, Journal of Reinforced Plastics, and Composites 37 (2016).

21. N. Kamar, M. Hossain, A. Khomenko, M. Haq, L. Drzal, A. Loos, Interlaminar reinforcement of glass fiber/epoxy composites with graphene nanoplatelets, Composites Part A Applied Science and Manufacturing 70 (2015) 82-92.

22. F. Li, Y. Liu, C.-B. Qu, H.-M. Xiao, Y. Hua, G.-X. Sui, S.-Y. Fu, Enhanced mechanical properties of short carbon fiber reinforced polyethersulfone composites by graphene oxide coating, Polymer 59 (2015).

23. S.-S. Du, F. Li, H.-M. Xiao, Y.-Q. Li, N. Hu, S.-Y. Fu, Tensile, and flexural properties of graphene oxide coated-short glass fiber reinforced polyethersulfone composites, Composites Part B Engineering 99 (2016).

24. M. Tarfaoui, K. Lafdi, I. Beloufa, D. Daloia, A. Muhsan, Effect of Graphene Nano-Additives on the Local Mechanical Behavior of Derived Polymer Nanocomposites, Polymers 10(6) (2018) 667.

25. M. Wang, C. Yan, L. Ma, Graphene Nanocomposites, (2012).

26. L.-C. Tang, Y.-J. Wan, D. Yan, Y.-B. Pei, L. Zhao, Y.-B. Li, L.-B. Wu, J.-X. Jiang, G.-Q. Lai, The effect of graphene dispersion on the mechanical properties of graphene/epoxy composites, Carbon 60 (2013) 16-27.

27. S. Lan-Hui, Z. Ounaies, X.-L. Gao, C. Whalen, Z.-G. Yang, Preparation, Characterization, and Modeling of Carbon Nanofiber/Epoxy Nanocomposites, Journal of Nanomaterials 2011 (2011).

28. R. Atif, I. Shyha, F. Inam, Mechanical, Thermal, and Electrical Properties of Graphene-Epoxy Nanocomposites-A Review, Polymers 8(8) (2016) 281.

29. S. Bal, Experimental Study of Mechanical and Electrical Properties of Carbon Nanofiber/epoxy Composites, Materials \& Design - MATER DESIGN 31 (2010).

30. X. Wang, W. Xing, P. Zhang, L. Song, H. Yang, Y. Hu, Covalent functionalization of graphene with organosilane and its use as a reinforcement in epoxy composites, Composites Science and Technology 72(6) (2012) 737-743.

\section{AUTHORS PROFILE}

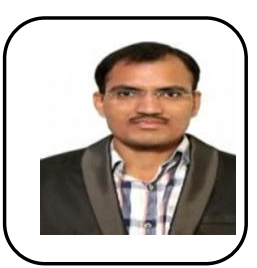

Mr. Ajmeera Ramesh, Assistant Professor in the Mechanical Engineering Department, CMR Technical Campus and a Research scholar in JNTU Hyderabad. He has seven years of teaching experience. His Area of Specialization is a lightweight advanced composite material.

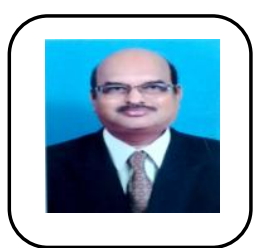

Dr. N.V. Srinivasulu, Professor in Mechanical Engineering Department, His Qualification is M. Tech, Ph.D. He has 30 years of teaching experience. His Area of Specialization is Plant Engg. \&Mgmt.: CAD/CAM, Vibrations.

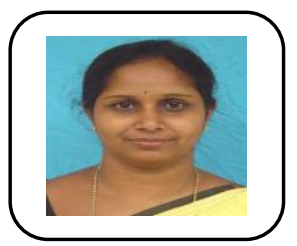

Dr. M Indira Rani, Professor in Mechanical Engineering Department, JNTUH College of Engineering, Hyderabad. Her Qualification is M.Tech, Ph.D. Specialized in Industrial Engineering. Her research interests include Industrial Engineering, Manufacturing, and lightweight advanced composite materials.

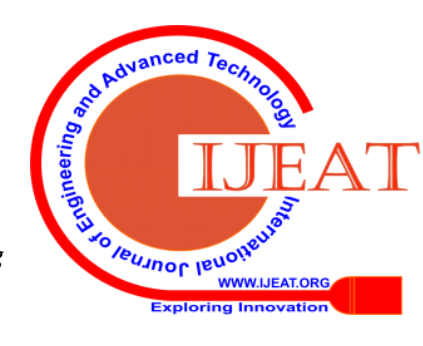

